\section{PRESIDENT'S ADDRESS,}

DELIVERED AT

THE FORTY-SIXTH ANNUAL MEETING OF THE BRITISH MEDICAL ASSOCIATION, Hald in BATH, August 6th, 7 th, 8th, and $9 t h, 1878$.

sy

\section{RANDLE WILBRAHAM FALCONER, M.D., F. R.C.R., D.C.L., \\ Consulding-Phrsician to the Royal United Hospital, Bath; etc.}

Gexrlemsn, -Thirty years ago, our Society, then known as "The Provincial Medical and Surgical Association", for the second time held its anniversary meeting in the city of Bath. Of those who were present on that occasion many, their life's labour finished, have gone over to the majority; others have sought their fortunes in distant localities; while of those who remain a few have readily united with another generation of practitioners to offer for the third time a cordial welcome to the members of the British Medical Association.

Since the annual meeting in 1848 , many changes have taken place in our Association. Then the business to be transacted occupied only two days, now it occupies nearly double that time; then there were only 1,300 or 1,400 members, now we have more than 7,500 . The annual income was about $6 x, 400$, while last year it amounted to more than EI 1,500. In 186\%, the Daily Fournal was first issued at the meeting in Dublin, and the sectional system first brought into practice. To the two addresses of Medicine and Surgery, a third has been added. Our Branches have increased in number, and this year for the first time we have a Colonial Branch, that of the island of Jamaica. These facts point to the extension of our power. The work actually done by the Association is manifested by the many Committees which hare been established for the promotion of those objects coming within its legitimate scope.

In the early days of our Association, the question of medical reform had attracted the serious attention of its members, and by their efforts in a great degree the first Medical Reform Bill receiped the sanction of Parliament. All that was then sought for was not obtained; but by the sedulous attention of the Medical Reform Committee appointed in 1852, up to the present time, advances have been made on the lines originally laid down by the Association, until this year the "one portal principle", or conjoint scheme of examination, has been made compulsory in the Medical Act Amendment Bill introduced by Government during the present session of Parliament; and many of the most prominent members of the General Medical Council have acknowledged that their own body requires reforming, and the necessity that exists for the representation of the great bulk of the profession in that Council. Towards the attainment of these important ends, your Medical Reform Committee has always directed the attention of the members of the Association, and this in no selfish spirit. The impression has erroneously gone abroad that representation in the General Medical Council has been sought for the Association only; but the true statement is, that the action of the Association has ever been on behalf of the whole of the profession, and for the whole profession have its energies and a proportion of its funds been expended. Complicated as this question may appear to be, there can be little doubt that it cannot be ignored in the future, and that, sooner or later, the just claims of the profession will be granted.

While the Medical Reform Committee was empowered to deliberate on this important subject, to another Committee was delegated the duty of watching the introduction into the Houses of Parliament of any Bills which, either directly or indirectly, were likely to affect the interests of the profession, whether Military or Naval, or the status of medical officers of the Poor-law or Public Health Services.

In 1863, a Parliamentary Committee was appointed, consisting of special members and representatives selected by every Branch of the Association. The reports of the proceedings of this Committee are recorded from time to time in the pages of our JourNal, and testify to the vigilance and activity of its members.

For a long time it had been held that, in order to estimate rightly the sanitary condition of a locality, so as to arrive at its true character as regards healthfulness, it was necessary to supplement the reports of the Registrar-General by returns, made at stated periods, of the prevalence of disease in relected districts, without reference to their mor- tality. To encourage this inquiry, and also to obtain the evidence of members of the Association upon medical questions having a practical bearing, a Registration of Disease Committee was appointed in 1865; its reports have always possessed great interest, and have been drawn up with much care and ability. It is only those who are acquainted with the difficulties which have to be overcome in prosecuting inquiries of this kind, under existing circumstances, who can estimate the true value of these reports.

In 1868 , when public attention was becoming alive to sanitary subjects, a joint Committee was formed, consisting of members of the British Medical Association and members of the Social Science Association, whose duty it was to consider all those subjects which are comprised under the term Public Medicine. The efforts made by this Committee to promote a radical change in sanitary administration, and also the memorial founded on the resolutions adopted at the Sanitary Conference held in London in 1876 , 2s well as the very valuable communications made to the Association by the members of this Commit. tee, those of the late Dr. Rumsey of Cheltenham, of Mr. Michacl and Dr. Stewart, bear testimony to the arduous exertions of this Committee.

For a long time, the Committee of Council, with the sanction of the Association, had at intervals, accurding to the financial state of the Association, granted sums of money for the promotion of original research ; on some occasions these grants were supplemented by subscriptions obtained from members of the Association. To these we owe the valuable reports made by the late Professor J. Hughes Bennett, "On the Action of Mercury", and the "Antagonism of Medicines"; but, as the funds of the Association increased, it was deemed desirable to appoint in 1874 a Scientific Grants Committee, who should select the subjects for investigation, and regulate the amount of pecuniary aid to be given in each instance. To this Committee the Association has hitherto annually given the sum of $\delta 300$ for distribution. Recently, the sum of $£ 100$, a special grant, has been placed at its disposal for the purpose of investigating the Pathology of Hydrophobia and Rabies. A preliminary report on this subject will be presented at this meeting by Dr. Burdon Sanderson and Mr. Callender. The investigations made by Professor Rutherford, Professor McKendrick, Drs. Braidwood and Vacher, and Dr. Fothergill, through grants provided by this Committee, have already been published in the JOURNAL.

In 1875 , the late Dr. Dalrymple of Norwich, and at one time the representative in Parliament of this city, devoted much attention to the condition of Habitual Drunkards, and drew aftention to the propriety, as well as necessity, of protecting the individual and his relatives from the evils of habitual intoxication. The Association, recognising the importance of this subject to the well-being of the community, appointed a Committee to consider the advisability of obtaining legislative restrictions applicable to Habitual Drunkards. This Committee has given much and continued attention to their special subject, and the result of their labours, with the assistance of Dr. Cameron, has been the introduction of a Bill into the House of Commons, which has passed a second reading. This is probably sufficient to indicate the satisfactory results of their deliberations.

In 1877, the question of Hospital Out-patient Reform was prominently brought to the notice of the Association, and a Committee was appointed to procure such changes in the administration of out-patient relief at hospitals as they might find necessary, and to carefully investigate and report on the working of the present system of provident dispensaries in Manchester. This Committee was appointed on the recommendation of the Public Medicine Section, at the meeting of the Association in Manchester last year. There can be no doubt that its report, which should be presented to this meeting, will contain much valuable material for discussion.

Among the awards offered by the Association, in addition to the Hastings Prize Medal, there was in 1875 a prize established to be given biennally, or less frequently, for the encouragement of original researches into the origin, spread, and prevention of epidemic diseases ; or such cognate subjects as the Committee of Council may determine. The amount of the prize consists of the accumulated interest of $£_{4} 400$, giren by Dr. Stewart, being part of a sum raised for a memorial of eminent services rendered by him to the Association.

In the present year, Mr. Middlemore of Birmingham has presented to the Association the sum of $£ 500$, the interest of which is to be given triennially to the author of the best essay on the scientific and practical value of the improvements which have taken place in Ophthalmic Medicine and Surgery during the previous three years.

This year, the Committee of Council determined on founding a medal for "Distinguished Merit", to be awarded to any member of the pro. fession, wherever residing and of any nation, for heroic conduct in the discharge of professional duties, or for special services rendered to the 
Association. The first presentations of this medal were made to the medical men who distinguished themselves in the well-known accident which occurred in the coal-mines near Pont-y-pridd, in Glamorganshire. The intrinsic value of this medal will, it is obvious, be enhanced by the unfrequency of its award.

Lastly, may be mentioned the changes which have been made in our JoORNAI, and the ability with which it is conducted by our editor, giving to it an influence and authority which is of the utmost maportance to the success and well-being of our Association.

Such are the means, wery briefly and imperfectly described, by whieb our Association seeks to promote the interests of our common professiom and the commenity at large.

The locality in which we are now assembled contrasts strongly with the busy scenes of manufacturing industry which, of late years, have been visibed by our Association. Bath is a residential city, vesorted to on account of its climate, especially favourable to those who have passed the meridian of life, on account also of the many advantages which it presents in a social and educational aspect, and on account of its mineral waters.

There is no manufactory of any great extent, if we except that of Messrs. Carr of Twerton, not far distant from the city, where a large quantity of the celebrated South of England cloth is fabricated.

Macaulay, in his History of England, referring to the state of Ongland in the sixteenth and seventeenth centuries, when speaking of the watering-places of England and their remarkable increase, adducing as examples Cheltenham, Brighton, Buxton, and Tunbridge Wells, goes an to say : "But at the head of the English watering-places, without a rival, was Bath. The springs of that city had been renowned in the days of the Romans. It had been during many centuries the seat of a bishop. The sick repaired thither from every part of the realm. The king sometimes held his court there. Nevertheless, Bath was then a maze of onty four or five hundred houses, crowded within an old wall in the ricinity of the Aron. Pictures of what were considered as the finest of those houses are still extant, and greatly resemble the lowest rag-shops and pot-houses of Rateliffe Highway. Even then, indeed, travellers complained of the narrowness and meannese of the streets. That beautiful city which charms even eyes familiar with the masterpieces of Bramante and Palladio, and which the genitus of Anstey and Smollett, of Frances Burney and of Jane Austen, has made classic ground, had not begun to exist. Milsom Stroet itself was an open feld lying far beyond the walls; and hedgerows intersected the space which is now covered by the Crescent and the Circus: The poor patients to mom the waters had been recommonded lay on straw in a place which, to use the languaige of a contemporary physician, was a eovert ther than a lodging. As to the comforts and luxuries which were to be found in the interior of the houses of Bath by the fashionable visitors who resorted thither in search of health or amusement, we possess information mare complete and minute than can generally be obtained on such subjects.

A writer who published an account of the city about sixty years after the Revolution, has accurately described the changes which had taken taken place within his own recollection. He assures us that in his younger days the gentlemen who visited the springs slept in rooms hardly as good as the garrets which he had lived to see occupied by footmen. The floors of the dining-rooms were uncarpeted, and were coloured brown with $\approx$ wash made of soot and small beer, in order to hide the dirt. Not a wainscot was painted. Not a hearth or a chimney-piece was of marble. A slab of common freestone, and fireirons which had cost from three to four shillings, were thought sufficient for any fireplace. The best apartments were hing with coarse woollen stuff, and were furnished with rush-bottomed chairs. The city, however, in a shont time was extended beyond the narrow limits within which it was confined, and in somewhat more than a century the larger buildings which give importance to its appearance were exected.

The city is built on each side of a valley through which the river Aron flows from east to west, making midway in its course a considerable bend, within which was the site of the Roman eity, and afterwards that of the mediæval and modern towns. From the right bank of the river, the land rises. by more or less gradual ascents nntil it peches the highest crest of Lansdown Hill, 8r3 feet above the level of the sea. On the left bank, the ascent is more gradual, but does not attrin the same altitude, the highest point, called Crossway; being 597 feet above the level of the sea. The larger portion of the town stands on the right bank of the river and extends up the hill. The humbler portion of the inhabitants reside in the vicinity of the river, while the business portion of the community occupy the site of the old town and somewhat beyond its boundaries, and the bigher levels are occupied by the more opulent inhabitants. The geological characters of the locality are deserving of notice.

The general aspect of the town, viewed from almost any of the surrounding elevations, is strikingly handsome, much of its appearance depending on the regularity of its buildings and of the material of which it is built, namely, the Bath oolite, which is abundant in the neighbouring hills, and is worked at a comparatively small cost. The appearance of the town as regards its physical beauty is mainly due to its geological character. There is a comparatively narrow track of alluvium at the bend of the river, and this is found also slightly to prevail on the east and west. On the lias which sincceeds it, the mach larger portion of the houses are erected, and extends from near the river northwards to a height of nearly 227 feet above the lower level of the town. Next to this comes the marlstone, forming a deep band, so to speak, which appears behind Camden Crescent on the east, and on which All Saints' Chapel is exected on the west; above this, again, is the inferior oolitic sand from which several springs arise used for domestic purposes. Above this is the inferior oalite on which Sion Place, a portion of Somerset Place, and Lamsdown Crescent, are built. Of this stratum, the whole of the upper part of Lansdown is formed, while, at Mount Reacon and Richmond Hill, there rests upon it a limited amount of fuller's earth. On the left bapk of the river, there is a large extent of alluvium on the east, which appears in a much less degree towards the west. In the former portion, especially in close proximity to Sydney Gardens, it is interspersed with gravel: on this side, there is a less extent of lias, while immediately above it is the inferior oolitic sand, and above this again the inferior oolitic limestone.

The buildings which stand on the eolitic limestones and sands rest on dry ground; those on the marlstone on ground more or less moist, while those on the lias and alluvial ground would be damp. In the lower part of the town, this is in a very great measure obviated by the large accumulation of the debris of former butilings, and from the houses being vaulted to a considerable height above the natural level of the soil, especially the North and Soath. Parades; while the old pietures which represent the original undulations of the soil in the upper part of the town show them to have been levelled by filling up the depressions, and by vaulting the buildings; a practice, it mas be observed, which is adopted in by far the larger portion of the whole town.

The waters of this place naturally divide themselves into two classes: first, the water employed for domestic purposes; and secondly, the mineral water. Of the latter, notice will be taken hereafter.

The history of this town shows it to hase increased in some instances, at considerable intervals of time, by the erection of targe stneets and masses of buildings, which led to the establishment of distinct companies for the supply of water to their inhabitants, or to a few streets by the individual owners of them. Down to 1835 , there were certain springs on Beechen Cliff, Beacon Hill, and Bathwiek Hill, which oonstituted the only water-supply in the possession of the Corporation for the use of their tenants, while the houses beyond the boundaries of the old city received their water from either private companies or from individuals. In 1851, the Bath City Act was passed; and this occurred at a time when sanitary measures were attracting public attention, and attempts were being made to abolish cesspools, and privies and ill.comstructed water-closets were being done a way with. This led to the larger use of water for domestic purposes. In this year, the estimated supply of water to each individual of the 2,38r water-tenants of the Copporation was calculated at six gallons a head. In 1861 , however, the num. ber of water-tenants had increased to 4,073 , and the supply amounted to thirteen gallons each; the steps taken by the Corporation in the interval between 1835 and $186 \mathbf{I}$ having increased the water-supply from 94,000 gallons to 348,000 gallons. In 1870, another Act was passed, and certain springs were acquired, the supply from which is known as the Monkswood Water, which yield daily 643,000 gallons, with a pressure of 230 feet. In addition to these, possession of two other springs, known as the Oakford and Eyford Springs, was obtained. The daily yield of water from these sources is 268,000 gallons ; "whilst, in winter, the flow almost exceeds computation". The result of this was that a daily allowance of water to the amount of seventeen gallons was given to each of the 53,000 inhabieants of the city, which, added to the previously existing supply, made a total daily allowance of twenty-six gallons to each individual. By the aequisition of other springs and waterworks, the property of private companies and individuals, the abore daily allowance of water wasincreased to twentyeight gallons to each of the same number of inhabitants. A valuable municipal report on this subject says: "Aetual figures would be na. reliable, but probably the increase of water thus obtained for domestic 
purposes would bring the dally allowance vess dose to the extreme raximum of thirts gallions per head, and thlo in aceondence with grag ings in dry seasons." Provision is made for the storage of water in reservoirs at Batheaston and also at Monkswood.

The number of hames supplied in the borough is 712 representing 50,128 inbabitants; outside the borougho 99 houses, representipg a population of 643.; giving a total of $50,77_{1}$ persons, Many, however, of the inhabitants are supplied with good water from wells and aprings, who are not included in the above calculation. The whole of the borough, however, is not supplied with water and this is attributable mainly to the varying levels of the locality ranging from 60 to 600 feet above the level of the sea. The tatal cost of providing the supply of water as it now exists amounted to $\{126 ; 343,45,2 d$. The average cost of the supply is about $3 \mathrm{~s}$. 7d. a year to each individual of the population, or, taking another calculation, the, price of $x$,oøo gallons is fourpence.

The greater portion of the city is supplied on the intermittent sys. tem, that is to say, water is turned on at stated times, and reserved for use in cisterns. When the supply of water was spall, this system was 2 necessity, and this arrangement prevailed in almost every house. The constant service system, where the pipgs are kept permanently charged with water, is both more efficient and economical; but the enormous cost to the inhabitants which new fitings would pecessitate is a serious obstraction in the way of this improvement.

But while the municipal authorities have been careful to provide an abundant supply of poter for the inhabitants they have been equally careful that the quality of the, water should be pure and wholesome. The whole, on by far the barger proportion, of the water is obtained from the oolitic and liassjastrata of the locality and its neighbourhood. Two analyses af the springe, have been made, one by the Rivers' Pol lution Compissioners and a second by Mr. Charles Ekin, chemist of

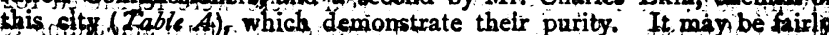
said that the water-supply for drinking and domestic purposes to the population of $\mathrm{Bath}$ is most abundant and wholesome.

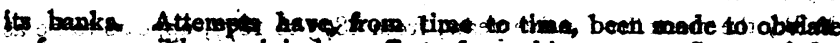
as far as possible any Injurious effects from this source. Somo of the drains thave been contingud to belet ibe ordinary water-level of the river, with a view to propent the eseape of gas; white the larget; which have, not boen prolonged into thes to 1 of the xireat, ane trapped with irop valpes. The cleansing of the thrter and rentoriang it an far as possible to its former vauated purity must be, after the iccompletion of the water-supply; the next care of our municipal authoritios. The mode which appears post feasible for this purpose is by interepting the senkgge at the banks of the river by a large drain, and so caurging it away from the town to a proper outfall.

Hoyseddajpage is on the whole in geod condition, and the sources of noxiaus smells are attributabl more to the cromelessness of the inhabitants of houses than to $a$ positive deficiency in the mede of drainage. The civil engineer states that cesspools, which at one time were very numerous, have been almost wholly abolished, and the old privies which were found in the courts, allies, small temements and in some of the best residences for the use of domestios, hared been placed by properly constructed olosets, with a good supply of tratpo.

Shughter houses, forty in number, are found in different places, chiefly in the lower parts of the town. They are under strict inspection, and are visited woekly, or more frequently if thought necessary, and are regulated by municipal by-laws, which are rarehy infringed. Some years aga an attempt was made to establish an abattoir spithout the boundaries of the city, and a considerable sum of money. was offered as a voluntary gift by two residents towards the of of its erection. The attempt, however, was unfortinnately not successfud.

The common lodging-houses eight in number, are all in one street, in the lower part of the town. They are kept in order under local by-laws i are:inspected weekly or oftener, as there may be need. The inspector of nuisances states that they are well kept both to general cleanliness and ventilation, and, in his opinion ar abtogetiot in better condition then houses of this character in most other pbaces. Most of the small tenemonts inhabited by the humbler members of

TABLE A. -Amalysis made by Mr. Charles Ekin, F.C.S., of 8, Argyls Sireat, Bart, 5th Aforck, 3878.

Thave analysed nipe samples of water received from Mr. Mitchell, labelled 1 to 9 , tach rample being contained in one of my own half-gallon glass-stoppered bottles. All the samples were bright and clear, witiout taste or sihell, and contained as follows :

Parts in 40,000, or grains per gatlon.

\begin{tabular}{|c|c|c|c|c|c|c|c|c|c|c|c|}
\hline \multirow[b]{2}{*}{ No. } & \multirow{2}{*}{$\begin{array}{cccc} & & & \\
& & & \end{array}$} & \multirow{2}{*}{$\begin{array}{ccc}\ddots & \ddots & \ddots \\
\ddots & \ddots \\
\ddots & \ddots \\
\end{array}$} & & \multirow{2}{*}{ Chlorine. } & \multirow{2}{*}{$\begin{array}{l}\text { Nigionerpa } \\
\text { Nitrates. }\end{array}$} & \multirow{2}{*}{ Nitrdgen a } & \multirow{2}{*}{ Arutanit. } & \multirow{2}{*}{$\begin{array}{c}\text { Albuminoid } \\
\text { Organic Mattec. }\end{array}$} & \multicolumn{3}{|c|}{ HAKDNBSt: } \\
\hline & & & & & & & & & Iemporaty. & Pettiantient: & Total. \\
\hline $\begin{array}{r}7 \\
2 \\
3 \\
4 \\
5 \\
6 \\
7 \\
7\end{array}$ & 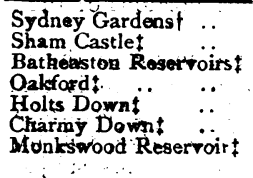 & $\begin{array}{l}\because \\
\ddot{*} \\
\cdots \\
\because \\
\cdots\end{array}$ & $\begin{array}{l}\because \\
\because \\
\because \\
\because \\
\therefore\end{array}$ & $\begin{array}{l}2.03 \\
1.88 \\
1.18 \\
2.2 \\
0.86 \\
0.78 \\
1.1\end{array}$ & $\begin{array}{l}0.18 \\
0.08 \\
6.14 \\
0.24 \\
0.23 \\
0.24 \\
0.24\end{array}$ & 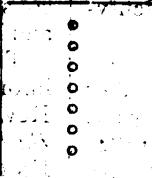 & {$\left[\begin{array}{c}0 \\
0 \\
0 \\
0.0015 \\
0.002 \\
0 \\
0 \\
0\end{array}\right.$} & $\begin{array}{l}0.072 \\
0.03 \\
0.064 \\
0.06 \\
0.046 \\
0.02 \\
0.049\end{array}$ & $\begin{array}{r}\times 4.3 \\
7.8 \\
63.6 \\
25.4 \\
x \times 0 \\
10.3 \\
\times 3.8\end{array}$ & $\begin{array}{l}6.9 \\
3.4 \\
4.4 \\
4.8 \\
4.9 \\
4.3 \\
4.4\end{array}$ & $\begin{array}{l}-1.2 \\
x \times .2 \\
t 8.0 \\
2012 \\
1.2 \\
1.2 \\
18.4 \\
18.2\end{array}$ \\
\hline
\end{tabular}

- Each degree of hardness is equal to one grain per gallon of carbonat of Kine, br fis equivalent ln other hardening salts, and indlcates the destriction and

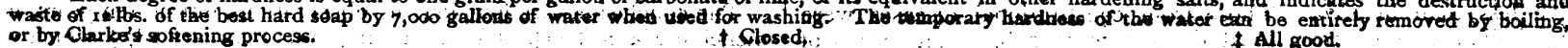

(Signed).

CRäles ERIF, F.C.S.

Analysis Publistind by the Rivers Pollution Commission.

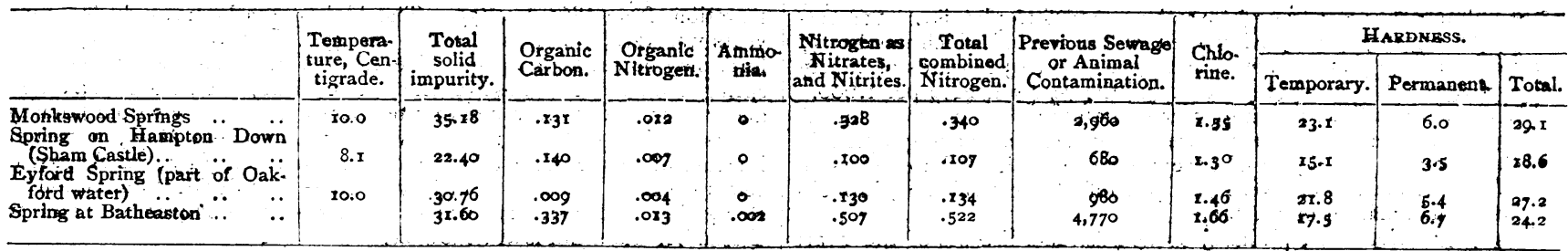

As regards sanitary arrangements, it will be noticed that, with the excoption of the lowest portion of the city, the ground upon which it is built presents great natural facilities for efficient drainage. The provisions made for carrying oway the sewrage, as well as surface-water, may be considered, as a whole, extremely good; neatly every portion hating sewers varying from $4 \mathrm{ft}$. $3 \mathrm{~g}$ in. to 9 in. in diameter, the larger ones being of an oval form, and constructed of stone; the latter of stoneware pipes. Uyfortunately, howevex, the whole of the material collecked by the sewage and drainage of the city finds its way into the river, which, if it were not in a great measure cleansed by the oociurence of floods and freshets from the watersheds of the neighbourhood and far distant hills, would be greatly detrimental to those who.inhabit the population, come under the motice of this officer. His wisits are rarely objected to, and, as a rule, they are found in a very satisfactory state.

The ratio of mortality to the pepulation of the borough, which, ac cording to the census of $187 \mathrm{r}$, was 32,585 , and this yen is estimated at 54562 , is generally high but liable to treme variations, The high rate, it is suggested, may be in a measure due to the influx of a large number of persons during oertain periods of the year, believad to amount to between 2,000 and 3,000 annually, to the advanced ages to which many. of the residents attain, or net improbably: to the number of deaths among children under five fears of age. On refertitr to the records of the medical affoer of healih, the bate Mr. Clement Barter, 
M.B., the mortality for five years, from 1873 to 1877 , appears to be as follows.

In 1873 , there were 1,277 deaths -329 referrable to general diseases, which term includes contagious, zymotic, and constitutional diseases ; 728 to local diseases, and 220 to conditions not necessarily associated with either general or local/diseases. Of the whole number of deaths, 380 occurred under five years of age, and 897 above that period. The death-rate was 24.2 per : 1,000. Epidemic measles, followed by bronchitis and pneumonia, caused a large number of deaths, especially among young children. Seventy-six deaths occurred from zymotic diseases; of these seventeen were from typhoid fever. Several cases of this ferer arose from the adulteration of milk with water which was reported by a competent authority to be "simply diluted sewage", and totally unfit for drinking purposes. Fifty:four persons died under the age of eighty, forty-nine under that of ninety, and ten under a hundred years.

The prevalent diseases of the year were acute bronchitis and pneumonia. From the former there were 120 deaths, of which sixty-four occurred in young persons under five years of age, and fifty-six at all ages above that point up to ninety. From pneumonia there were sixtyfour deaths-thirty-seven under five years of age, and twenty-seven above it. There were also seventy deaths from chronic bronchitis oc curring wholly in persons between the ages of fifty and one hundred.

In 1874, the total number of deaths was 1,222 , or fifty-five less than in the preceding year-206 died of general diseases, thirty-three less than in 1873; 728 of local diseases, the same as in the previous year ; and 198 of diseases not of the general or constitutional class, being twenty-two less than in 1873 . Pulmonary diseases caused a large proportion of deaths this year. The temperature at the latter part of the year was very low. In 1874 , affections of the lungs and air-passages prevailed, which proved fatal to both the young and those advanced in life. There were eighteen deaths from whooping-cough-seventeen occurring in children under five years of age ; II4 deaths from phthisis, of which III occurred in those above five years of age, and specially fatal to those whose ages varied from ten to seventy years; ro3 deaths were recorded from acute bronchitis, of which there were sixty, fiftyone of which occurred between the ages of fifty and eighty. The deaths among young children amounted to forty-three, and were confined to those from under one month to three years of age.

The death-rate from zymotic or contagious diseases was slightly more than one per $x, \infty \infty$, and the number of deaths was sixteen less than in the previous year. 124 persons are reported to have died of old age, Io9 being upwards of seventy years of age, and sixteen above ninety. The number of deaths under five years of age was seventyfive, or 305 less than in 1873 .

In 1875, the rate of mortality rose to a height which it reached on three occasions only during the preceding fifteen years. The number of deaths was 1,310, being eighty-eight in excess of the past year This increase is attributed to the severe weather of the winter of 1874 75 ; the sanitary condition and arrangements of the city being very good. Forty-eight deaths only of the zymotic class were registered, twelve less than in 1874 . Those from constitutional diseases were 263 ; while the deaths from local diseases were 248 , or an excess of eighty-eight over the same class in 1874. There was a large mortality from diseases of the organs of respiration, amounting to 298 ; $20 \mathrm{r}$ vere attributed to bronchitis, 62 to inflammation of the lungs, 13 to pulmonary congestion, 7 to asthma, and 6 to pleurisy. 114 persons were registered as having died of old age, of which number 57 were above eighty and under ninety years, and 13 upwards of ninety years of age. The average mortality of the year was 24.9. per 1,000 .

This year was marked by a greater rainfall than had occurred for fifteen years (1862); 39.811 inches were registered as having fallen in 198 days ; and it was a year of exceptional mortality; the diseases of most frequent occurrence were phthisis, infantile convulsions, bronchitis, and inflammation of the lungs.

In 1876 , scarlet fever, phthisis, bronchitis, and diseases of the heart contributed the largest number of deaths to the mortality.

In this year, Mr. Clement Barter, M.B., the medical officer of health, died, to the great regret of his many friends, after having very conscientiously performed his duties. He was succeeded by $\mathrm{Dr}$. Brabazon, the present medical officer of health, from whose report the remainder of the information for the years $1876-7$ is obtained.

Owing, however, to the decease of the former medical officer of health, and the necessary interval before the appointment of his successor, the reports are not so full and complete for the whole of this as for preceding years. As far as can be ascertained, the deaths from all eaises amounted to 1,334 , showing an increase of twenty-four over the year 1875. Of the zymotic and constitutional class there were 326 deaths, of which there were I04 from scarlet fever, and seventeen from typhoid fever. Of local diseases there were $5 \mathrm{II}$ cases; of these 99 were due to phthisis, 40 to paralysis, and 129 to bronchitis; ... Eightytwo died of old age, one of whom was ninety-nine years of age. The average mortality of the year was 21.2 per 1,000 .

In 1877, the mortality had fallen to 1,153 , or 181 deaths less than in the previous jear. To zymotic or contagious diseases 333 deaths were attributable; to local affections, 579; to other causes, 241. There were 52 deaths from measles, 98 from phthisis, 134 from bronchitis, 103 from diseases of the heart, 120 from old 2 ge, of which fifty-three were between sixty and eighty years of age, and sixty-six.were eighty and upwands. The average mortality for the year was 21.6 per 1,000 . It is, however, deserving of notice that the total mortality during the month of November in this year fell to 5.9 per 1,000 .

Some interest, as was before alluded to, has from time to time been shown in reference to the high mortality of this place, and various explanations have been suggested to account for it. By some it has been attributed to deaths occurring among the large number of sick folk who resort hither for their health's sake. This latter is purely conjectural, inasmuch as no data exist by which it can be supported.

The ratio of mortality in 1873 was 24.2 per 1,000 ; in $1874,23.2$; in $1875,24.9$; in 1876, 21.2 ; and in $1877,21.6$-giving an average for these five years of 23 per $x, 000$, or a fraction, .5 , more than the annual rate, 22.5, of mortality for England and Wales, and 1.9 less than the annual mortality, 24.9, for the urban registration districts.

The deaths of children under five years of age in Bath in 1873 were 380 ; in 1874,302 ; in 1875,303 ; in 1876,308 ; in 1877,313 -the total, amounting to 1606 , giving an average for this period of 321 per annum, or 6.11 per cent. of the whole population. The deaths of those of sixty years of age and upwards were, in 1873, 469; in 1874, 486 ; in 1875,511 ; in 1876 (in this year serenteen ages were not given), $364 ;$; in 1877,455 , in which year there were registered 102 deaths of persons of eighty years and upwards-the total amounting to 2,285 , an arerage of 457 per annum, or 8.70 per cent. of the whole population.

In referring to the climate of Bath, Dr. Granville, in his Handbook to the Hot Springs of Bath, 1841, remarks that "some say that it is cold, others that it is temperate : there are those who insist on its perfect dryness, while many contend that its prevailing dampness from frequent rain is notorious. Lastly, we hear often of its rariableness and exposure to strong winds, and nearly as often this statement has been contradicted". These opinions may be reconciled when the variableness of the climate of the South-Western District is taken into consideration, and the positions of the various portions of the locality, and its geological features are borne in mind.

The most recent and valuable contribution made to the following information which exists regarding the climate of Bath is that by the Rev. Leonard Blomefield, and published in the Proseedings of the Bath Natural History and Antiquarian Field Club, rol. iii, No. 3. From this source the most reliable information on this subject is obtained.

The conclusions are founded on observations during ten years, commencing March 1865, and terminating with February 1875, which were made at the Bath Literary and Scientific Institution.

The mean temperature of Bath from nine years' observation, i.e., from $1866-74$ is 50.5 , and the result is the same from ten years' observations from 1865 to 1875 . The highest yearly mean during nine years was 52.0, while the lowest was 49.4 in 1870 ; the range, therefore, may be set at $2.6 \mathrm{deg}$. The months in excess occur chiefly in spring and summer; those in which a deficiency occurs are in autumn and winter. The mean monthly temperature rises slowly from January to $\mathrm{March}$, but makes a rapid advance in April and May; a greater increase of temperature takes place in June and July; in August it remains nearly the same as in July. There is a decided diminution in September and October, which is increased in November, and in December the mean is at its lowest.

The greatest heat in the ten years' observations occurred in the years 1868-70; the maximum being $90.5 \mathrm{deg}$. in 1868 . There is no year in which it did not attain to $83 \mathrm{deg}$; the mean absolute highest for the whole period being $87 \mathrm{deg}$.

The greatest cold occurs in December and January: once it occurred in February and in March during the nine years observed.

The mean monthly range, or mean difference between the highest temperature and the lowest in each month, is least in February, being Io.o deg., November, December, January, and March, having no very marked difference, but the range is in all greater than that of February by three degrees or more. A considerable rise occurs in April and May, and the monthly range $17.6 \mathrm{deg}$. gains its maximum in the latter month. 
The mean daily range rises from the lowest, $9.6 \mathrm{deg}$, in January to its bighest, $17.8 \mathrm{deg}$., in July. The greatest rise occurs in April, the daily range of which month is $3.4 \mathrm{deg}$. in excess of that of March.

As regards the seasons of the year, the mean temperature of spring varies from $47.4 \mathrm{deg}$. to $50.5 \mathrm{deg}$., the range being $3.1 \mathrm{deg}$; ; that of summer from 60.0 deg. to 63.5 deg.; the range being 3.5 deg.; of autumn, the variation is from $48.5 \mathrm{deg}$. to $52.7 \mathrm{deg}$.; the range being 4.2. deg.

Mr. Blomefield, in comparing the temperature of Bath with Oxford, Greenwich, Royston, and Norwich, comes to the following conclusions : "In spring, Bath has a higher mean temperature, while the night temperatures are not so low, and the mean daity range is less, when compared with Greenwich and Royston especially. In summer, the mean temperature is not different from that of the other towns, but the extreme night and day temperatures are both of them more moderate, the mean daily range being still more contracted than in spring, in relation to those towns. In autumn, the mean temperature is only very slightly higher than that of other places; the extreme day temperatures scarcely so high as some of them, but the nights are not so cold, the minimum not falling so low. In winter, the mean temperature is decidedly higher, the extreme day and night temperature also both higher, though the mean daily range shows scarce any difference."

Comparing the temperature of Bath with that of Exeter and Clifton, premising, however, that the series of observations made by Dr. Shapter of Exeter and Dr. Burder of Clifton are not for the exact same periods as those made at Bath, it is found that the first four months of the year are colder than at Bath, the mean difference in favour of the latter locality, amounting to I.I deg. May and June have a lower mean temperature at Bath than in Exeter; while the months of October, November, and December, 'are colder 'in Bath than in Exeter, the mean difference in favour of Exeter being $1.7 \mathrm{deg}$. The mean temperature for the whole year is 50.7 deg. - higher than the mean yearly temperature at Bath, though only by two-tenths of a degree.

As regards Clifton, the mean temperature of every month excepting October is lower there than at Bath; the greatest difference is found in the first four months of the year, the difference amounts to $3.2 \mathrm{deg}$., Clifton being much colder than Bath at that season. The least difference between the two localities is found in May, June, and August the difference, however, amounts to only I. 7 deg. The mean temperature for the whole year at Clifton is given by Dr. Burder at $48.4 \mathrm{deg}$., or more than two degrees below that of Bath.

If Bath be compared with Taunton, Barnstaple, and Truro, its temperature is lower than either of the lastnamed places in all seasons except summer. In winter, the difference is more than two degrees as compared with Barnstaple, and three degrees as compared with Truro.

So far as existing observations show, the temperatures of Bath and Taunton are not very dissimilar; but in autumn and winter, the mean diurnal range is more than two degrees greater at Taunton than at Bath.

As regards the relative humidity of the climate of Bath, it is. less humid in spring than either of the three towns abovementioned, no great difference existing between Bath and Truro. In autumn, the humidity is nearly the same as that of Barnstaple, but in excess of Taunton and Truro. In winter, Bath is less humid than Taunton, and not very different from Barnstaple and Truro. The whole comparison appears to be that Bath, in relation to places either eastward or westward, has an excess of humidity during summer and autumn, but a deficiency in winter and spring.

The mean yearly rainfall at Bath is estimated by $\mathrm{Mr}$. Blomefield at 29.986 inches, and, "allowing for errors", he adds, "it might probably be set at 30 inches at least, if not more". The mean fall of rain in spring amounts to 5.492 inches; in summer, 6.227 inches; in autumn, to 8.892 inches; and in winter, to 9.730 inches. From this, it appears that the rainfall is least in spring, increases in summer and autumn, and is greatest in winter. The driest period of the year in Bath is, on an average, the months from March to June, both included. In none of these months does the mean fall of rain amount to two inches, the least fall occurring in June. . Rain appears to fall on r60.9 days of the year. Heavy falls of rain are of short duration, and the heaviest do not exceed an inch and a half. An exceptionally large amount occurred in the very wet year of 1875 in July, when it reached 2.750 inches in twenty-four hours. The annual rainfall at Exeter is, according to Dr. Shapter, from observations extending over forty-four years, 29 inches, or nearly one inch less than that of Bath, while that of Clifton is stated by Dr. Burder to be 31.02 inches, or one inch more than that of Bath. Observations, however, said to have been carried on in continuation of Dr. Burder, for. twenty-two years, ending with 1874 , the mean yearly fall of rain at Clifton is stated to be 32. 194 inches, or more than two inches above the Bath average; but this statement might admit of modification, if observations, at both places were made for an equal period and for identicaj years. There are variations in the estimate of the rainfall in different localities not far distant, and varying in their height above the leyel of the sea, depending upon the form of and elevation of the neighbourhood of Bath, which materiatly affects all such observations. But, however great the rainfalt here may be, the natural and artificial drainage is so favourable that it would not be at all difficult, even in some of the lower portions of the town, to find, after even a heavy fall of min, many spots where exercise on dry ground may be enjoyed.

A few remarks on the prevailing winds may fitly close these statements. The most prevalent winds are those from the west and northwest quarter of the compass: The north and north-east winds reach their maximum in spring, as in most other places in England. The south and south-west winds attain their maximum in winter, and are least frequent in summer. The west and north-west winds characterise the summer months, while in every season except winter they predominate over all others. Southeast winds seldom continue long, though more frequent in spring than at other periods of the year,

The mineral waters of Bath, to which the origin and celebrity of the city are due, present to the physician, as well as to the student of natural phenomena, an objeck of interest. Among the earliest indications of their use are the remains of Roman edifices and baths in close proximity to the springs, In 1755 , the ruins of a bath were found on the south side of the Abbey Church which occupied an area of two hundred and forty feet from east to west, and one hundred and twenty feet at the broadest part, from north to south and were highly decorated with tesselated pavements, columns, pilasters and every prnament of classical architecture. The remains, also, of a temple dedicated to Sul Minerva, probably the equiyalent of the Pantheon of Minef Medica, which was found among the more remarkable structures at Rome, was discovered when digging the foundation of the present Pump Room.

In 676 of the present era, Osric, who built a monastery here, visited its hot waters; and Offa, about a century afterwards, made it the residence of his court for some time. Athelstan and Edgar are also said to have delighted in the use of its medicinal springs, and indeed almost all the Saxon kings either visited Batb, or enriched it by their munif. cence.

In I 106, John de Villula, Bishop of Bath and Wells, built two new baths for the convenience of the monastery within its precincts, one of which he named the Abbot's Bath, and dedicated to the use of the public, while the other was reserved for the use of the prior of the monastery.

In 1138 , Robert, Bishop of Bath and Wells, founded a hospital for lepers, and dedicated it to .St. Lazarus, attaching to it a bath called the Leper's or Lazour's Bath, which was supplied by the overflowings of the Hot Bath situated close to it. This bath was remaining, but little used, in 1773 . The period at which it was destroyed is uncertain. The hospital contained seven beds. A somewhat grotesque representation of the lepers resting after bathing will be found in Guidott's treatise on the Bath Waters, published in $169 \mathrm{r}$.

The baths remained in the possession of the priors and monks of the Benedictine Monastery of Bath until the dissolution of religious houses in the time of Henry the Eighth.

Leland, not long before this period, visited Bath, and mentions the Crosse Bath, sa called "bycause it hath a cross erected in the midle of it". "This bath", he says, "is much frequented of people diseased with lepre, pokkes, scabbes, and great aches, and is temperate and pleasant". He then goes on to speak of the "Hote Bathe" and the "King's Bathe". Of the former he remarks, "This is caullid the Hote Bathe ; for at cumming into it, men think that it wold scald the flesch at first, but after that the flesch is warmid it is more tolerable and pleasaunt." The cross to which I eland refers appears to have been replaced by another erected by John Drummond, Earl of Melfort, Secretary of State to James the Second, in commemoration of his queen having used the baths with happy results in 1688 . This cross becoming dilapidated, was removed in 1783 . In 1590 , Queen Elizabeth granted a new charter to the city, by which the possession of the mineral springs and baths was confirmed to the Mayor and citizens of Bath. In 1668, Pepys visited Bath, and records his visit under date June 15 th thus: "Looked into the baths and find the King and Queen's full of a mixed sort, of good and bad, and the Cross only almost for gentry, so home with my wife, and did pay my guides, two women, 5s., one man, 2s. 6d."

At the present time, there are four establishments for bathing, named, the King and Queen's Private Baths, the Royal Private Baths, the Hot Bath, the Cross Bath, and the New Royal Private Baths, the latter 


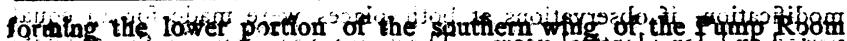

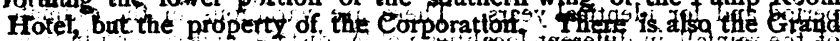

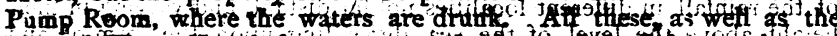

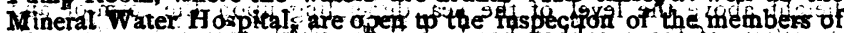

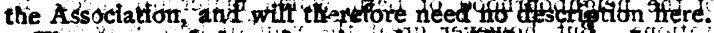

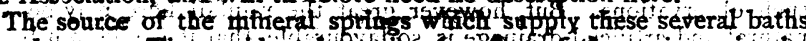

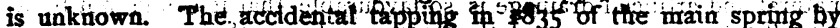

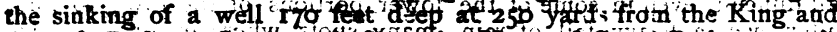

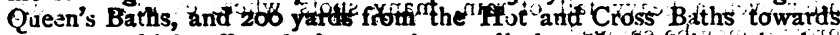
the west, which affected the supply to all these batfis, "fixes the ime

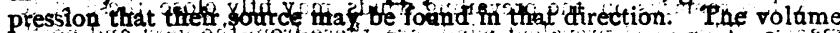

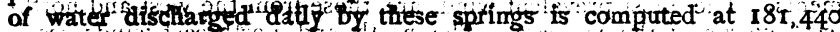
gallons:

It is trot ingrobabte that the find titeir way through fissures or dislocationis un the' lfas, upper reth sandstones, and marls, and also in the cont rinestures and the fact that particles of coal are found among the satid throw to by them tends to give support to this impressibn. Har spritis ftequently occur neat the litie of juriction of two gélogical formations, atid thóse of $\mathrm{Ba}$ th arise near the junction of the lias with the ypper oolite.

The tetuperature of the water of all the sprtings appears to have been coristatit, excépt on three occarions. The spring supplyitin the Hot bath Has a temperdture of izo deg. Foth of the King's bath

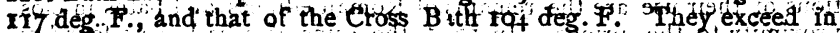
temperature all the watm springs in Ekis cotantry

The peat of the springs has been reptesented as arising from the action of a votcano beneath the town but on the one hand the presence of thermal waters is by no means altwys connected with

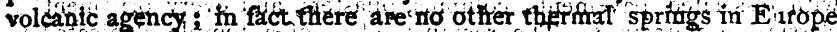
which sise so far trenoved from the region of earthquakes or active volcanic atency and on the other the beological fextures of the district indicate a trapquil depostion of the muteriats contistituting the several strata," while the separation betweeti the tipper stratum of the high land of the valley is more properly to be ascribed to denudation than the throes of a volcano, at a time probatfy when the valley formed part of an estuary, the waters of which debouctied in the direction of Weston-super-Mare, over a tract of country now known as the Zoylands (i.e., sea lands), while the fisstutes and distocations of the lower strata, through which the mineral waters reach the surface, may be attributed to disturbing causes acting from a distance. It is more reasonable to attribute the heat of the bath waters to a cause to which both thermal springs and tolcanoes may be satisfactorily referrednamely the central heat of the eartt, than to any local subterranean volcanic fire.

The quantity of water, supplied by the springs, which amounts to 181,440 , gallons daily, appears to have been unaffected, since they first became subjects of investigation up to the present time, by any meteorological change. They are, as an old witer has said, Perennial springs, whose water is neitber increased by the greatest glut of rain nor lessened by the greatest dradght". The eonstancy of their flow into the baths has been thrice interrapted; once by the sinking of a shaft in search of coal in the neighbourhood of Batheaston, towards the east; again, in 181 , when an escape of water toob place from the springs, rendering it necessary to "s puddle" the ground through which they rise ; and, more recently, in 1835 , by the digging of a well $r 70 \mathrm{ft}$. deèp, at a distance on the west of $25^{\circ}$ yards frotrin the King 's and Queen's Baths and 200 yards from the Hot and Cross Batls. The stream of hot water burst into and overfluwed the well and the supply to all the baths was materially diminished, as also the temparature of the water ; the latter circumstance may be accounted for by the water in the baths cooling more rapidly when but slowly suppli $=d$ to them. The stream, however, was with some difficulty restored tó its nátural channel, and the baths afterwards filfed in the usual time. "Fhe solid contents of the daily discharge of water is computed by Professor Ramsay to be 3,402 lbs, or 420 tons a year. According to this authority, "a cubic yard of limestone maj be toughly estimated to weigk one ton. If, therefore, these salts were compressed and solidified into the same bulk as limestone, we should find the annual discharge of the Bith wells to form a square column oft. in diameter and $140 \mathrm{ft}$. high". (Physical Geology and Geography of Great-Brit:zin, p. I 17. .)

In small quantities, when recently drawn from the spring, the water is clear, eolourless, and sparkling. In large quantities, it presents a pale, sea-green tint. It is free from any odour, and possesses a.pungent, slightly saline, and somewhat chalybeate or inky taste, and, though perhaps a little distasteful at first, the invalid with whom it agrees in a short time comes to relish it.

The Bath waters have been frequently analysed. The water examined was in each instance drawn from the King's Bath spring, the specific gravity being 1.002 . They were analysed in 1806 by P'illips, in 1820

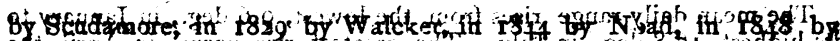

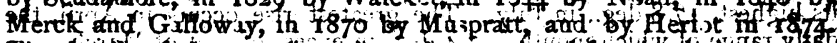
The fetatls of these anatyses have bee printed for ctrcufatiof d th ineéting (Tabte 8$)$ :

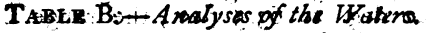

\begin{tabular}{|c|c|c|c|c|c|}
\hline $\begin{array}{l}\text { In an Imperial Gallon, } \\
70,0 \text {, Graitss }\end{array}$ & $\begin{array}{l}\text { Phillips. } \\
\text { s806. }\end{array}$ & $\begin{array}{l}\text { Scuda- } \\
\text { more. } \\
1820\end{array}$ & Walcker. & $\begin{array}{l}\text { Noad. } \\
1844\end{array}$ & $\begin{array}{c}\text { Merche and } \\
\text { Gadlown } \\
1848 .\end{array}$ \\
\hline 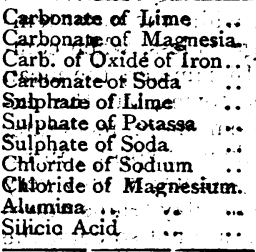 & $\begin{array}{c}7.680 \\
0.274 \\
80.400 \\
.0 \\
14.400 \\
31.680 \\
.0 \\
. .960 !\end{array}$ & 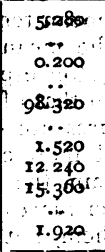 & 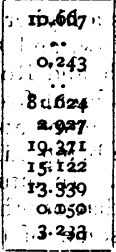 & 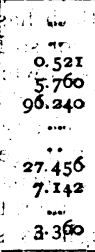 & 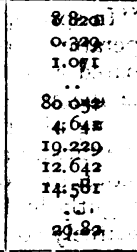 \\
\hline wan idirectly absetwed. & $\begin{array}{l}\text { r42.394 } \\
\text { r44-120s: }\end{array}$ & & $\begin{array}{l}x_{4} 6.676^{\prime} \\
x_{4} \neq 602\end{array}$ & $\begin{array}{l}140.479 \\
\times 49167^{\prime}\end{array}$ & 144.018 \\
\hline rbonig, $A$ & II.2pc.j, & & soc. $\mathrm{i}$ & $\because$ & $\begin{array}{l}26.45 f\left(\frac{1}{6}\right) \\
\text { at } 1+5^{\circ}\end{array}$ \\
\hline
\end{tabular}

Ipding and Manganese traces, by Morckiand Galloway fithium and Stronj tiun, by Roscoe, i86e-64. Gases: Nutrogen or per cent. (Daubeney); Carbonic.

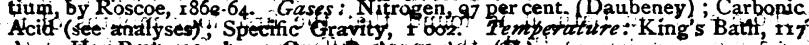

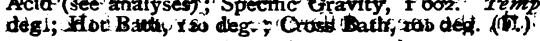

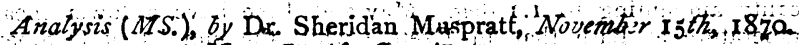
Mean Specific Gravity, I.003,1742.

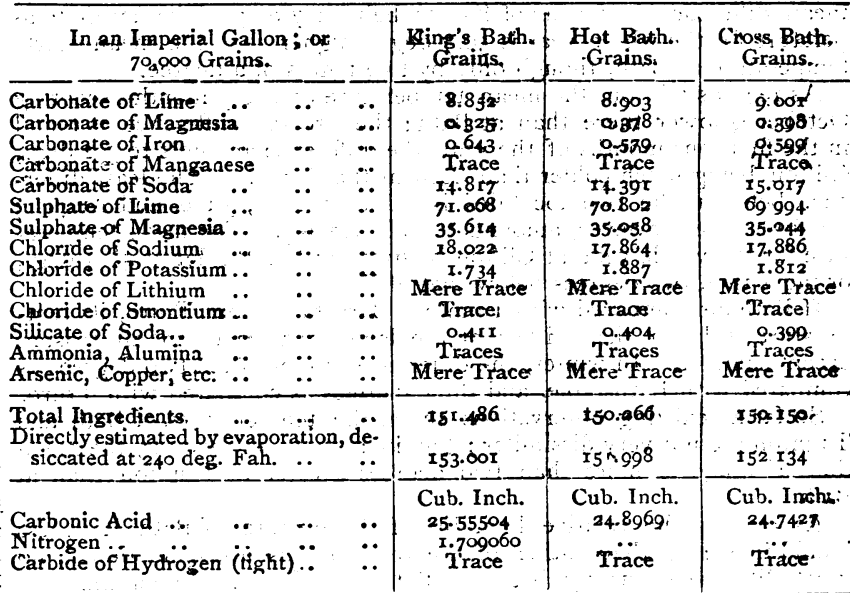

Analysis by Mackay Heriot, F,G.S. (Gaptain R.M.L.I.)

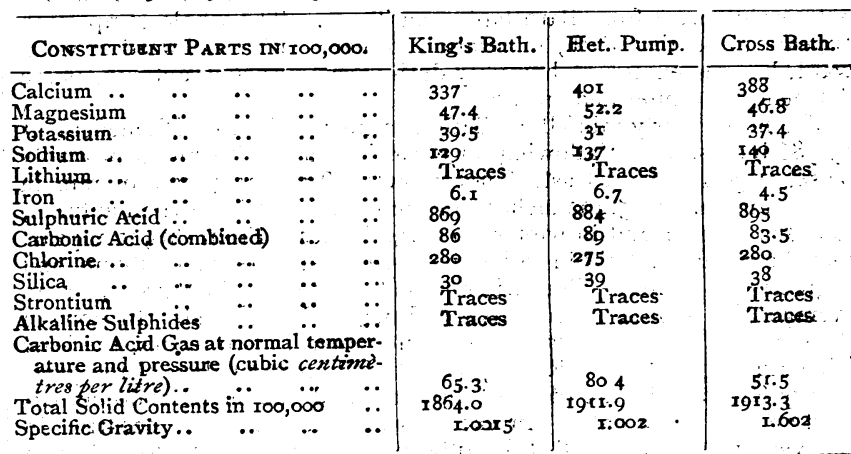

Temperature: King's Bath, xI7 deg. F. ; H.ot Bath, 120 deg. F.; Cross Bath ra4 deg. F. The Nitrogen daily evolv ed from the Springs amounts to about 250 cubic feet.

Cuff is said to have detected iodine in the waters ; Noad remarks in reference to this substance that, "accorling to Stromeyer, starch will detect free iodine in a liquid containing. $-\frac{1}{5} \overline{0}-$ th of $i$ ts weight of that principle ; if therefore any iodine does exist in the Bath waters, it must be in a proportion less than the above, and probab!y beyond the reach 
of chemical detection". 3 Menck and Galloway found traces of bolh iodine and manganese. The latter had been previously detected by Mr. -R. Biggs of this place. Gibbs first. detected silex and Scudamore magnesia. Roscoe of Manchester, discovered lithium and strontium.

The small amount of mineral ingredients cantained in these waters, the lowest estimate being 134 , and the highest $15 \mathrm{I}$ grains in an imperial gallon, has not unfrequently been referred to as a valid reason against their efficacy. It is, however, worthy of notice that many of the well known Continental springs, which have long enjoyed and still continue to maintain a deserved reputation in promating recovery from the diseases in which they have been found to be efficacious, oontain a considerahly smaller proportion of ingredients than the Bath waters.

The most abundant ingredients of the waters, taking the analysis as $a$ whole, are : I. Sulphate of lime; 2 Chloride of sodium; 3 . Chloride of magnesium; and 4. Sulphate of soda. The: propartion of iron which has teen detected is comparatively small; still its taste is guite perceptible in the water, and its effects on the system are more decided than could have been expected from the small porticn which has hitherto been revealed by analysis. It is found plentifully, in com. bination with lime and magnesia, deposited in the channels through which the water is conveyed to the private baths, and also on the pavements of the fublic baths.

The gases evolved from the waters are carbonic acid, nitrogen, and oxygen. The result of Professor Daubeney's investigations, as stated by him in a paper read at the meeting of the British Association, beld in Bath in 1864, is as follows." "The spring that supplies the King"s and Queen's Baths the most of any, discharges $28 \mathrm{I}$ gallons of water, or, in round numbers (reokoning 277 cubic inches to the gallon), 34.900 cubic inches per minute. - Of this water, 100 cubic inches were found by me to disengage, after long continued broiling, $31 / 4$ cubic inches of air, consisting of 2.9 cubic inches of carbonic acid, 0.4 of nitrogen, and 0.2 of oxygen, so that there will be present in 34.900 cubic inches of carbonic acid 1.012; nitrogen, 140; oxygen, 70 : which quantity, added to that of the free gas disengaged per minute from the spring, would make up the following amount--viz, carbonio acid present in the water, I.O12, disengaged or free, 12 -total, 1.024 nitrogen present in the water, 140 ; free, 245 -total 385 ; axygen present, 70 ; free, ditto, 10-80-total $\mathrm{r}, 489$ cubic inches."

As egards the carbonic acid found in these sptings, the analyses by Merck and Galloway, and also by Muspratt, give somewhat more than three cubic inches of this gas to each pint of water; while the earlier analysis by Phillips gives somewhat more, and that by Walcker some what less, than one cubic inch to the same quantity of fluid.

The quantity of nitrogen contained in the Bath waters, amounting to 97 per cent. of the gaseous matter yielded by them, is deserving of notice, Dr. Lyon Playfair, writing on the gaseous contents of the Buxton water, obseives that "the gases are nearly of the same compo. sition as those of the thermal spring at Bath, and there is no reason to doubt that dissolved carbonic acid and nitrogen nray exert important physiological effect $\mathrm{s}$ ". It is difficult to explain precisely the manner in which nitrogen, from such sources, produces a bepeficial effect on the system i but that it holds important relations with the animal economy is undoubted.

Some time since, Professor Williamson was kind enough to favour me with the following communication on the gaseous contents of the King's Bath spring. "The mean of two analyses of one specimen in which all the constituents. were determined gave nitrogen 96.222 , carbonic acid 3.002 , oxygen .578 , marsh gas .198. With respect to the quantity of gas evolved from the King's Bath spring (the orly ane examined) the mean of six measurements gives 2297 cubic centimètres per minute, It seems unquestionable that atmospheric air is acted upon by carbonaceous deposits which are evolving marsh gas by their decomposition, and that carbonic acid is formed at the expense of the greater part of the oxygen of the air. Most of the carbonic acid, no doubt, remains dissolved in the water"

It may here be mentioned that vegetable matter is found at certain seasons of the year floating on the surface of the mineral water, adher. ing to small masses of its deposit and sometimes adhering to the walls of the open baths ; it consists of the Oscillatoria or Conferva tenuissima first found in the Bath waters, and described by the late Dr. John Fqrd Davies. "Its singular appearance", observes Sir J. E. Smith "arises from the filaments being collected together into little ascending tufts; apparently rooted in the muddy. deposit of the water. Each tuft proves on examination to consist of simple reniform, even filaments, crowded together and quite pellucid, and equally destitute of joints and branches; their diameter is not more than the 8 .1000th or 10,000th part of an inch."

It is not, however, to the presence of one or more particular mineral ingredients of a spring, except where they are foupd in lange propor- tops that its efficacp is to besttributed, ar on pwich its selection as a medicinal agent widl depend, if is to the union of the several substances contained in the ofter whe guantity for fluid with which they are combined, and still more to the recomded emperience and concurrent testimony of credible witnesses, that wo must chiefly refer for instruction and guidance in the choice and employment of a mineral spripg.

When the waters aro drank fresh from the spring, they raise and accelerate the pulse, increase the temperature of the bodx, and excite the secretions; and these effects, which are generally manifested soon after drinking them, ane more permanent than might at first be anticipated. : They have a tendency to produce constipation when taken in small quantities : but the older writers mention their purgative effects ; the dose, however, they administered amounted to one, two, or three quarts daily, which produced two or three copious evacuations. The ordinary quantity, pamely, foux, six or eight ounces taken daily, tends to produce a regular action of the bowels, while a larger quantity will sometimes cause purging.

The effects of the waters, which indicate that they will prove beneficial by drinking of them, are a glow of warmth in the stomach, an increased appetite, an improvement of the spirits, an augmented secretion of the saliva, and an excitement of the urinary discharge; the latter constituting one of the best indications of their being likely to produce a good effect ; next to which may be placed the rapidity with which they quench thirst. If, however, they produce headache, thirst, a dry tongue, a sense of weight in the stomach, diminish rather than improve the appetite, induce nausea and sickness, and fail in promoting the flow of uruge they will be of no advantage undess their tendency to cause these effects can be obriated. This may in many instances be brought about by diminishing the dose, by altering the period of the day at which they are taken, hy allowing the water to cool before drinking it, and especially by relinquishing their use before breakfast. The employment for a short time of some diuretic remedy, conjaintly with the water will aid in deciding its effect $\$ 0$ as to augment the flow of urine. But if these changes are, unattended by any corresponding result, no benefit can be expected from persisting in their use.

The quaptity of water to be drumk during the day should, ynder ondinary circumstances, be divided into two portions, one of which may be taken before breakfast, and the other in the afternoon. The usual amount taken at one time varies from four ounces to half a pint. It may, however, be increased to double that quantity, if the smaller doses do not disagree, and the case requires it. If the quantity to be drunk be large, the morning and afternoon partions should be divided, ten minutes or a quarter of an hour being allowed to intervene between the divided dose, which time will be usefully occupied in gentle exercise. The water should be drunk leisurely, for nothing is more likely to cause discomfort than rapidly tossing off the quantity directed to be taken. There is no objection to drinking the waters on the same day that the bath is used.

When the waters are used as a, hath, 2 slight shock, accompanied with chilliness, is often experienced on fisst entering the water, which soon passes away, and is suaceeded by a gxateful sensation of warmth. The frequency of the pulse and the temperature of the body is increased, and subsequently the amount of the urinary discharge augmented. After the use of the bath; there is a consciousness of elasticity and vigour of the frame, and the appetite is improved. The exhausting perspira. tion and fainting which offen follow the use of warm baths of ordinary water, rarely, if ever occur aftor the employment of the mineral water neither is its use,productive, under ordinary circumstances, of the copious perspiration consequent on common tot baths. In cases where the limbs are stiffened, or contracted by rheunatism, the power of moving them is gradually restored in many cases it returns with remarkable quickness by means of bathing, The same result also takes place, though more slowly, in certain cases of palsy, in which the employment of the bath is allowable. Pain also is relieved during the use af the bath, as in sciatica; and though it and the stiffness of the limbs often returp at first, soan after leaving, the bath, it will be observed that the interval between employing the bath and the recurrence, of pain or stiffness increases, until they are entirely removed. In some cases where bathing does not disagres and yet does not produce any very appreciable effect at the time, it is advisable, after.a proper trial, to cease from using the bath ; for aftentimes ;elief or recovery follows after its employment has been discontinued, or after an interval its use may be resumed with manifest ad wantage.

When the use of the hath is attended with marked repdness of the skin, flushing of the face $2 p d$ giddiness, the temperature of the water should be lowered and the period for employing it diminished, until both are adapted to che requirements of the case; but if after taking these precautions, similar effects be still produced, it will be evident that the use of the waler, in this mode, must be relinquished. 
The temperature of the bath, under ordinary circumstances, should not exceed 95 deg. or 97 deg. Fahrenheit. A higher degree of heat ought never to be resorted to, except by special direetion. The proper time for remaining in the bath should not exceed ten minutes, or a quarter of an hour, when used for the first time : sometimes five minutes may be sufficient at first; and it is from inattention to this point, that many persons have relinquished the use of the waters, after a single trial, alarm having been created by the giddiness and flushing of the face, from incautiously remaining too long a time in the water. Provided no discomfort is experienced; the period may be extended to twenty minutes or half an hour, according to the effect produced. The bather should descend gradually into the bath, and on leaving it be enveloped in a warm sheet, covered with a warm blanket. The sheet, aided by gentle friction, absorbs the moisture from the body; and when this has been done, it should be allowed to slip down, and the warm blanket wrapped round the person; the bather may then return to the dressing-room, and after being well rubbed with warm towels, proceed to dress. Where it is considered necessary to promote perspiration, the bather should immediately, on being enveloped in the sheet and blanket, proceed to the dressing-room, lie down on the bed or sofa, and being wrapped in one or two warm blankets, remain there for about a quarter of an hour, then be rubbed, and dress. The same rules should be observed on leaving the open baths. If the weather permits, it is well to walk for a short time after bathing, or else to return home and rest.

The best time for taking a bath is early in the morning, during the warm months of the year, though it is usual to select an hour between two and five o'clock in the spring and autumn, and an earlier hour during the winter. But it may be employed generally at any period of the day, provided it be not soon after, or only a short time before, a meal. It may ordinarily be taken three times in the week; in some cases, as often as four or five times within that period.

The above remarks may be taken as general rules, to be observed in employing the waters either for bathing or for drinking ; but the special circumstances of every individual case will decide to what extent a deviation from them is allowable. It is well known that some persons can use the waters without experiencing any injurious effects, but it is equally well known that many persons suffer from their in. judicious employment.

Douching, etc.-Dry pumping, as the use of the douche alone, without a bath, is termed, in contradistinction to the wet or subaqueous douche, i.e., the employment of the douche when in the bath, may be used at any period of the day; the forenoon, however, is the most desirable time. The use of the dry douche is regulated by the time during which it is applied. The wet douche is used after the bather has been for awhile in the bath, the duration of its employment being regulated in the same manner as the dry douche. The bather should not remain in the bath after the douching has been completed. The douche ascendante may be used at whatever period of the day may be most convenient. The lavement is used with the most marked advantage before breakfast, and may be also beneficially used an hour or two after that meal. It is especially serviceable in cases of habitual constipation, and in cases where the regular action of the bowels has been interfered with by the injudicious and indiscriminate use of purgatives.

Among the disorders which derive benefit from the use of the Bath waters are those of the digestive organs. Invalids who suffer from these affections do not generally have recourse to mineral waters until their complaints have assumed a chronic form, manifested in a pale yellow, or what is called a bilious complexion, with diminished or an almost entire want of appetite, foul taste in the mouth, accompanied by weight and oppression, referred to the stomach, constipation or diarrhoea, with cold hands and feet, depressed spirits, and an indisposition for occupation of any kind. In such cases, the Bath waters produce very beneficial effects; where constipation is present, the occasional use of the lavement contributes to their realisation. An old writer on these waters has observed that "every medical practitioner at this place has seen instances of people labouring under want of appetite; pain and spasm of stomach and bowels, together with all the other symptoms of depraved digestion, and want of power in the proper organs to perform their functions, joined to a very great degree of weakness, both of the body and of the spirits, relieved by the use of the Bath waters. The recovery in such cases is particularly remarkable from its taking place so quickly after the commencement of the trial of the remedy. A few days will frequently work such a change in the situation of the patient as would be scarcely credible, were it of less common occurrence. The appetite is often restored altogether, the wandering spasm and pain cease, the natural rest returns, and the spirits are raised to their proper pitch. The strength lik and the natural secretions and regularity of the body, in point of evacuation, are restored".

In anæmia and amenorrhœa, the waters have been found by long experience to be a most effectual remedy. The bath is generally: the best form in which to use them, and the employment of the douche ascendante will materially contribute to promote beneficial results. In dysmenorrhœe, also, the bath, with or without the wet douche, affords great relief. In leucorrhoa, also, it is. useful when employed in the same mode.

In cases of gout, the waters have long been celebrated for the relief which they afford; and where anomalous affections of the head, stomach, and bowels, are attributable to latent gout, the use of the warm bath will bring on a "fit"; by which they are generally removed. It, however, often happens that by the repetition of acute attacks, the disturbance of the digestive organs does not subside, but harasses the sufferer in the intervals between the paroxysms. In alleviating and removing this condition, the waters taken internally are peculiarly beneficial. They act as a cordial, without producing ary heating effects; and their influence is soon shown in an improved appetite, a more regular action of the bowels, and in the altered character of the urine. They are also useful in cases where deposits are commencing in the joints of the hands and feet. In atonic gout, a judicious employment of the waters often protects the patient for lengthened periods from a recurrence of an attack. In the acute form of gout, the waters are inadmissible; but in recurring slight attacks, they may be freely used. The temperature of the bath in cases of this kind should be carefully attended to.

In rheumatism, the greatest benefit is derived from the use of the waters. In acute rheumatism, after the subsidence of feverish symptoms, the employment of the tepid bath is extremely grateful, and accelerates recovery, and retards, if it do not prevent, this form of rheumatism from becoming chronic. In subacute rheumatism, also, its use is followed by beneficial results. In chronic rheumatism, after many remedies have failed, as numerous cases admitted into the Bath Mineral Water Hospital prove, the waters, when used internally and externally, seldom fail to give relief, and very frequently effect recovery. In sciatica and other forms of neuralgic rheumatism, the waters in the form of a douche, or bath, are extremely serviceable. In rheumatic arthritis, the use of the baths, commencing with a temperature of 95 deg. or $96 \mathrm{deg}$., and increased to $100 \mathrm{deg}$., if the patient can bear it, together with employment of the douche in the bath, produces, in a short time, relief. The drinking of the waters, at the same time, also conduces to accelerate recovery. The amount, however, of benefit afforded by the waters will depend on the length of the time during which the patient has suffered from disease, as well as on the period for which the waters are used. In lumbago, the use of the douche three or four times a week, or more frequently, in a short time gives relief.

In hemiplegia, where the brain has been involved, use of the water cannot seriously, on the whole, be said to afford very great relief. Instances, however, are adduced where the contrary result is reported to have taken place. If used, it ought not to be employed until some time after the seizure. In palsies arising from cold, or from the introduction of mineral substances into the system, such as lead, arsenic, mercury, copper, the use of the waters has been attended with great benefit, and particularly in that form of palsy which affects the wrists of painters, gilders, and compositors, known as "dropped hands". In such cases, the Bath waters have been for many years known as a valuable remedy. At one time, the number of cases of this kind admitted into the Mineral Water Hospital was large : of late years, the number has diminished, which may be attributed to the greater care taken to avoid the poison, and the successful use of other remedies. Generally speaking, the worst cases come to the Hospital.

In ischias, or hip-disease, the waters have afforded great benefit, but it is only at its early stage that advantage can be looked for from their employment. In chorea, bathing and douching down the whole back several times in the week, is productive of good results; and here, again, the effects of the waters are more evident in young than in adult patients.

In cases of syphilitic and gonorrhœal rheumatism and syphilitic cutaneous eruptions, especially if, in the last mentioned state, it happen that the patient has been under the influence of mercury, the use of the waters, both by drinking and bathing, is followed by beneficial effects.

Lepra, eczema, psoriasis, and other cutaneous diseases, many of which are traceable to or associated with 2 gouty or rheumatic diathesis, are effectually relieved, and in very many instances cured, by bathing. It is generally desirable, in such cases, to commence with a tepid bath, and gradually increase the temperature. 
In weakness of the limbs, arising from injury; in the stiffness fol. lowing the fixed position in which it is necessary to preserve the fractured limbs; and in sprains; and in the contractions of the lower limbs sometimes following severe attacks of fever; in slow recovery of the use from dislocation, bathing and douching are efficacious in restoring the limbs to a healthy condition.

During convalescence from protracted sickness, the Bath waters may be classed among the most desirable and grateful tonics which can be taken; and formerly it was almost an invariable custom for convales. cents, especially for women recovering from their accouchements, to take a short course of the waters, which habit, of late years, seems to have been relinquished without sufficient reason.

The abovementioned diseases may be regarded as among the principal in which relief or recovery may be expected from the use of the Bath waters. It would not have been difficult to increase their number, but my present object is simply to indicate some of the chief affections in which the waters may be beneficially employed. It may here be mentioned that patients trequently recover after they have ceased to use the waters, who, while using them, were not sensible of benefit during their employment.

The best seasons of the year for the use of the waters are spring and autumn. The months of April, May, and June, in the former period, and the close of August, September, and October, in the latter, are the best months to resort to their employment. It is not to be understood that the waters cannot be used in winter, inasmuch as every arrangement is provided for facilitating their use during that season. But their use during the latter period may be interrupted, their regular employment interfered with, and consequently delay the development of their curative effects, and preclude exercise also in the open air, which assists their action, and is used with so much advan. tage during the time they are employed. Reason and long experience have justified the propriety of the preference given to the spring and auturnn of the year.

The effects of the Bath waters in promoting recovery from or ameliorating the symptoms of those diseases in which their use is likely to be beneficial, may be best shown by the results obtained in the Bath General or Mineral Water Hospital.

During nine years, from 1870 to $1878,2,384$ patients were admitted under my care in this hospital; of whom 1,699 were males, and 685 were females. Of the 1,699 males, fifty-six were discharged as cases not suited for the use of the waters, fourteen left the hospital at their own request, six died, and one was discharged for improper conduct. Of the remaining $1,622,311$ recovered, 922 were much better, 236 were better, and 153 were no better. As it will be necessary frequently to make use of the terms, "recovered", "much better", " better", and " no better", it may be well to state, that in ninety-nine cases out of a hundred, the decision of the conditions of the patients on their discharge is declared by themselives. This, in a great measure, diminishes the number of those "recovered" and augments the number of those " much better", inasmuch as many included among the latter class, at the time they are discharged, often complain of some very slight pain, risking the chance of being allowed a longer residence in the hospital.

Of the 685 women, 15 were discharged as unfit cases for the waters, four left at their own desire, one died, none were discharged for improper conduct. Of the remaining 665,107 recovered, 365 were much better, 120 better, and 73 no better.

Taking the whole number of males and females, amounting to 2,287 , 418 recovered, 1,287 were very much better, 356 better, and 226 no better. Of the whole number, 1,699 males which were admitted, 936 suffered from rheumatism in one form or another, 254 from gout, 128 from sciatica, 82 from paralysis, 40 from lead palsy (dropped hands), 32 from affections of the hip, 26 from eczema, 17 from psoriasis, six from lepra, two from pityriasis, and one from sycosis, leaving 175 suffering from less urgent maladies.;

Of the 685 females, 455 suffered from various forms of rheumatism, 33 from gout, 32 from paralysis, 24 from psoriasis, 19 from sciatica, 18 from eczema, 16 from chorea, 12 from anæmia, 6 from dropped hands, and 2 from pityriasis, leaving 62 suffering from minor forms of illness.

The average duration of the illness of each male patient previous to admission is neatly two years and a half, and of their stay in the hospital fifty-seven days; while that of the females is nearly two years and a quarter, and of their residence in the hospital sixty-nine days.

Of the 1,699 male patients, 77 were discharged as improper cases, or from other causes, leaving 1,622 under treatment. Of these, 3 II recovered, or 19.18 per cent.; 922 were much better, or 55.84 per cent.; and 236 , or 14.55 better. There were 153 no better, or 9.43 per cent.

Of the 685 females admitted, twenty were discharged as improper cases, or from other causes, leaving 665 under treatment; of these, 107, or 16.09 per cent. recovered; 365 , or 54.89 per cent., were much better; and 120, or 18.04 per cebt, better; seventy-three, or 10.98 per cent., no better.

If these results in both sexes be combined, there were 2,287 patients treated: of these, 418 , or 18.28 per cent., recovered ; 1,287 , or 56.27 per cent., were much better ; 356 , or 15.57 per cerit., were better ; while 226 , or $9: 88$, were no better.

These are the results of my own cases for eight years, and they do not represent the most favourable results. It may be added that other remedies, especially those of an anti-rheumatic kind; were, as a general rule, never employed.

If the Hospital Register be referred to, it will be seen that; during the year 1877,475 cases of rheumatism were admitted : of which, sixtythree recovered, 380 were relieved, twenty-six no better, three improper, and two discharged at their own request, or for misbehaviour, and one died. Eighty-four cases under the heading of sciatica, lumbago, and neuralgia, were admitted-fourteen recovered, sixty-three were relieved, five no better, two discharged at their own request, or for misbehaviour. One hundred and eight cases of gout-ten recovered, eighty-nine relieved, three no better, one improper, two discharged, three died. Twenty cases of paralysis-fourteen relieved, three no better. Thirtythree cases of lead palsy admitted-four recovered, twenty-seven relieved, two no better. Two cases of wasting palsy, no better. Two cases of locomotor ataxy, no hetter. Thirty-eight cases of leprosy, psoriasis, eczema, and other cutaneous diseases : of which, twelve recovered, twenty-three were relieved, one no better, one improper, one left at his own request. Seven cases of chorea-four recovered, three relieved. Seven cases of anæmia-one recovered, five relieved, one no better. Three cases of hysteria - two relieved, one no better. Rigidity and other diseases of the joints, etc., twenty-three-two recovered, seven relieved, seven no better, six improper, one discharged at his own request. The average stay in the hospital was fifty-nine days.

It should be remembered that, almost without exception, the cases admitted into the hospital have undergone a great variety of treatment before their admission, some for many years, that special selection of cases is not practised, but all for whom there appears to be a probability of relief are admitted. Considered in this light, the mineral waters are a remedy of undoubted value. It may safely be said of them that they recover many, relieve more, and comfort all.

There yet remains a duty, grave, though pleasing, which I have to discharge. It is, to offer to the Association my sincere, though inadequate, thanks, for the honour conferred upon me, by electing me President of this great Association. It will be my aim to perform the duties of that distinguished office with the best powers I possess. In the shadow, however, of an event which has saddened the hearts of so many friends and associates, one naturally shrinks from alluding to the future; but, "favente summo Numine", I trust that, by our united endeavours, this Association will advance in influence and usefulness - that its influence will always be for good, and its usefulness manifested in strenuous endeavours to ameliorate the sufferings of humanity; and that those who on this occasion have the pleasure of ministering to the promotion of the objects of the Association, and to your individual enjoyment, may have the happiness of knowing their efforts have not been unsuccessful, and of indulging the pleasant hope that in future years many will, with unalloyed pleasure, recal to their memories their visit to "The Baeth" of England, and the "WATrRS OF THE SUN".

The BRITISH Association.-GREAT preparations are being made in Dublin to give éclat to the approaching meeting of the Association. The first general meeting will be held on Wednesday next, when Professor Allen Thomson will resign the chair to the President-elect, Mr. William Spottiswoode. All the sectional meetings will be held in Trinity College, the Provost and Senior Fellows having generously not only placed the most suitable lecture-rooms and halls at the disposal of the Local Executive Committee, but also charged themselves with the expense of adapting the same for the occasion. The medical profession is well represented on the different sections. In Section B, Chemical Science, Dr. Maxwell Simpson is President, and Professors Apjohn and Emerson Reynolds, Vice-Presidents. Professor Flower presides over the Biological section; the Vice-Presidents of which are Professor Huxley and Dr. Robert McDonnell; and the Honorary Secretaries include Dr. Reuben J. Harvey, Dr. Hayden, Professor McNab, and Professor Purser. A large number of medical visitors are expected to attend the meeting, and the President and Fellows of the King and Queen's College of Physicians have issued cards of invitation for a dinner to be given in the College Hall on ${ }^{-M}$ Monday the 19 th inst. A conversasione will be given in the Royal College of Surgeons the same evening, and the College "Club" will entertain a number of guests to dinner on the 2 Ist inst. 